\title{
Assessment of Therapeutic Efficacy of 5\% Sodium Hydrocarbonate Solution in Case of Nodular Dermatitis of Cattle
}

\author{
Sh V Vatsaev ${ }^{1}$, O Yu Chernykh², A A Lysenko ${ }^{3}$, M Sh Gaplaev, and A M Plieva ${ }^{5}$ \\ 'Department of Veterinary, Medicine and Zoo Engineering, Chechen State University, Grozny, \\ Russia \\ ${ }^{2}$ Kropotkinskaya Regional Veterinary Laboratory, Department of Epizootology, Microbiology, \\ Virology, Kuban State Agrarian University, Kropotkin, Russia \\ ${ }^{3}$ Department of Therapy and Pharmacology, Kuban State Agrarian University, Krasnodar, Russia \\ ${ }^{4}$ Chelyabinsk Research Institute of Agriculture, Grozny, Russia \\ ${ }^{5}$ Department of Biological Research, Complex Research Institute named after Kh.l. Ibragimova, \\ RAS, Grozny, Russia
}

\section{Abstract}

This article provides information on studies and evaluations of therapeutic efficacy of 5 $\%$ sodium bicarbonate solution in case of nodular dermatitis of cattle. Due to the market expansion of veterinary drugs, the periodization of unusual and new medicines as well

Corresponding Author:

Sh V Vatsaev

vac-60@mail.ru

Received: 25 October 2019

Accepted: 15 November 2019

Published: 25 November 2019

Publishing services provided by

Knowledge E

(c) Sh V Vatsaev et al. This article is distributed under the terms of the Creative Commons

Attribution License, which permits unrestricted use and redistribution provided that the original author and source are credited.

Selection and Peer-review under the responsibility of the AgroSMART 2019 Conference Committee. as control methods of pathogens of farm livestock, having therapeutic and prophylactic effect, is under permanent control of specialists in the field of veterinary medicine. Recently the importance of finding modern means and methods of dealing with animal diseases aimed at the restoration of the body homeostasis has increased significantly in order to ensure the physiologically normal functioning of many enzymes, hormones and the whole body. There is a need for their rational use based on the study of changes in clinical and biochemical parameters occurring in the body under their influence and other factors contributing to the development of normal physiological status of the body (homeostasis). Based on the above, the present studies were based not only on etiological and pathogenetic, but also sanogenetic ideas about diseases with the aim of choosing the means that form the body's normal physiological status (body homeostasis restoration), taking into account physiological characteristics of animals, and thereby providing the best medical and prophylactic efficacy [4]. Periodization of new drugs and methods to combat animal diseases that contribute to the restoration of body homeostasis is very important. This importantance has become even more significant since the increased sanitary and hygienic requirements for the use of veterinary drugs in animal husbandry, primarily for the treatment of dairy animals, which will serve as a guarantee for obtaining livestock products safe from the point of view of veterinary and sanitary norms and excellent sanitary quality.

Keywords: Contagious nodular dermatitis (Lumpy skin disease, LSD), blood $\mathrm{pH}$, constancy of intercellular fluid composition, acid-base composition of blood, physiological parameters, homeostasis. 


\section{Introduction}

Nodular dermatitis (Lumpy skin disease, skin tuberculosis, nodular exanthema, Dermatitis nodularis bovum) is viral, emergent, transnational, contagious infectious disease of cattle characterized by the formation of nodules in the skin (nodes, tubercles), persistent fever, edema of subcutaneous tissue and internal organs, lesions of the lymphatic system, eyes, mucous membranes of respiratory and digestive systems [6].

Lumpy skin disease (tubercle, nodular dermatitis, nodular exanthema) is a widespread desease causing significant economic damage to livestock [4].

Usually, the outbreaks of lumpy skin disease are sporadic. However, besides the sporadic cases of diseases, the group morbidity of animals is periodically observed. Sometimes such outbreaks of nodular dermatitis include dozens of sick animals. Group diseases of animals do not occur in the places where animals were vaccinated with smallpox vaccine of sheep and goats. At the same time, there were the cases of identifying sick animals among the cattle vaccinated with smallpox vaccine of sheep and goats, but only during the incubation period [1, 3].

Lumpy skin disease causes skin lesions in the form of nodules, abortions of cows and heifers, reduced milk yields and body weight, temporary or permanent infertility of manufacturing bulls, as well as death of animals, which most often occurs from the secondary diseases and causes significant economic damage to livestock [6].

Under normal physiological conditions, all life processes in the body occur in aqueous media with a certain concentration of hydrogen atoms, which means a certain acid-base balance (an indicator of free hydrogen atoms in solution) [7].

The blood normally has a weak alkaline reaction, i.e. 7.35-7.45. It should be noted that normal functioning of many enzymes, hormones and the whole organism is possible only with such a reaction. In case of pathological phenomena, i.e. with acidifying or alkalizing factors the compensatory mechanisms, so-called "buffer systems", operate in the body and it is much easier to acidify the body rather than to alkalize it [7].

Due to the disruption of physiological equilibrium between the level of acid and alkali in the body, all body systems begin to malfunction [7].

The body is constantly struggling to prevent blood $\mathrm{pH}$ from going beyond the physiological limits, in this case the acidification, which is mainly carried out by leaching calcium from bones and massive release through kidneys [7].

At the same time, osteoporosis (weakness of bones), disruption of joints, weakness, pain and muscle destruction are observed. Moreover, the development of pathological phenomena in the renal system (stone formation, the occurrence of inflammatory 
phenomena, renal failure), central nervous disorders, cardiovascular and respiratory systems, hypofunction of endocrine glands and many other pathological phenomena, including cancer are caused by this desease $[4,7]$.

The development of measures to combat nodular dermatitis is a serious economic issue, the success of which largely depends on the effectiveness of the means and methods of control [2].

It should be borne in mind that many veterinary drugs are not recommend for dairy cattle, as they tend to persist in animals for a certain time and is excreted in milk [3].

These data indicate that neither researchers nor farmers yet have the drugs that fully meet their requirements. The search for the drug is still an urgent problem [8].

The complexity of measures against nodular dermatitis, to a certain extent, lies in the fact that they are carried out in the pasture period, summer time, at various stages of the disease [3].

In the system of measures to combat nodular dermatitis, an important place is occupied by regular preventive treatment of animals with insecticidal and repellent agents aimed at deterring, eliminating or reducing the number of insects as one of the potential carriers of the pathogen [3].

A considerable economic damage caused by flying insects confronts us with the need to carry out special activities in the summertime piriod, i.e. during the period that determines the formation of an epizootic type of pathogen, which means that even unaffected animals should be subjected to prophylactic treatments in order to protect them from the attack of flying insects. Moreover, forced medical care should be provided to animals during clinical manifestation of this disease $[1,3]$.

Therefore, in the implementation of control and prevention measures, an important role is played by breaking the epizootic chain and stopping the growth of insect number, i.e. treating animals for preventive purposes during the pasture period, in order to protect them from insect attacks $[3,5]$.

In the system of control and prophylaxis with animal diseases of a contagious and non-contagious nature, including nodular dermatitis, it is very important to restore homeostasis and maintain dynamic balance in the body, restore the body's physiological ability to self-regulate and overcome the pathogenic effects of disease-causing agents [2].

Out of the numerous regulations peculiar to higher animals and humans those that ensure the constancy of mineral and acid-base composition of blood work most accurately [2, 8]. 
Due to the disruption of physiological equilibrium between the level of acid and alkali in the body, all body systems demonsrate malfunction [2].

The above indicates that in order to ensure optimal conditions for the functioning in the physiological mode of all cells of the body, especially brain cells, veterinary specialists face the need to develop such physiological mechanisms that would preserve the constancy of composition of intercellular fluid and blood plasma (internal body environment) [2].

Specialists in the field of veterinary medicine should ensure that functioning of the infectious and parasitic system is carried out on the basis of interdependent adaptive changes in the populations of parasite (antigen) and the host, so that under various pathological conditions and cellular processes followed by the change in the salt composition of the body's aquatic environment the physiological equilibrium between the level of acid and alkali in the body remain the same [2].

Animal physiological processes demonstrate the fact that the use of such drugs that have a pronounced and selective preservation activity is becoming more and more important in the system of measures to combat various infectious and non-contagious diseases of animals or restoration of constancy of intercellular fluid and blood plasma composition (homeostasis), i.e. restoration of physiological ability of organism [2].

The analysis of existing information shows that there is nothing concerning the administration of veterinary drugs that have activity to maintain the constancy of composition of intercellular fluid and blood plasma. Besides, there is no comparative analysis of biochemical changes occurring in the body of cattle under the influence of $5 \%$ sodium hydrogen carbonate solution in case of nodular dermatitis of cattle [2].

The study of these issues along with the introduction of research results into veterinary practice can serve as a methodological basis for scientifically-based system for combating this highly contagious infection, improving animals' productivity, meat quality and raw materials of animal origin [2].

\section{Methods and Materials}

The studies were carried out by the method of expeditionary and stationary observations in the livestock facilities using the methods of epizootological examination, clinical, biochemical and experimental studies in veterinary medicine.

The studies were carried based on common methodologies, in the flat zone of the Chechen Republic, in a personal farm of a resident of the settlement of Kalinovskaya station, Naur rural area. 
The blood samples were taken from 7 cows with nodular dermatitis in the initial stage of the disease, with typical clinical signs, regardless of productivity, sex, age and body weight; 2 hours, 4 hours, 8 hours, 24 hours, 48 and 72 hours after administration.

7 cows were selected with clinical form of disease, regardless of productivity, sex, age and body weight for the experiment. The diagnosis was carried out according to the instructions, taking into account clinical signs and laboratory tests.

The animal blood was taken from the jugular vein in the morning before feeding. For the collection of serum, $10 \mathrm{ml}$ vacuum tubes for the collection of venous blood as a coagulant containing BD Vacutainer CAT (Clot Activator Tube) were used. The studies were carried out using an IRF-454B2M refractometer (KOMZ, Russia) and a Humalyzer 2000 analyzer, in Kropotkinskaya Regional Veterinary Laboratory.

In the process of biochemical studies, the content of creatinine, carotene, total protein, $\mathrm{Ca}, \mathrm{P}, \mathrm{AsAT}$, AIAT, glucose, Vit. E, urea, alkaline phosphatase, reserve alkalinity, immunoglobulins $A, G, M$ was determined.

\section{Results}

When studying the influence of both biotic and abiotic factors on the development of causative agent of cattle nodular dermatitis, it has been established that more uniform landscape and climatic conditions in the lowland and foothill zones of the Chechen Republic, the diversity of species composition and earlier and mass flight of insects, as well as longer pasture period during which animals may come in contact with pathogens are favorable factors for the development of pathogen in the external environment and the formation of big natural infection pools.

Nodular dermatitis in cattle is accompanied by manifestation of pathological changes in the organism of sick animals of atopic, inflammatory and dystrophic nature, which leads to acidification (acidosis) of the internal environment of the body, to the effects of creatinine hyperfermentemia (Table 1).

The analysis of laboratory studies of the blood of a patient with bovine nodular dermatitis allows us to determine the negative acid load on the organism of these animals (Table 1).

As the sick cattle body had to compensate for the imbalance of mineral substances with its own alkaline reserves, i.e. with mineral substances (calcium, sodium, potassium, iron) guided by the need to restore the $\mathrm{pH}$ of blood as well mas other biochemical processes in the body (homeostasis) and increase the level of oxygen in cells, we applied the intravenous infusion with $5 \%$ sodium bicarbonate solution. 
This drug was selected taking into account the fact that $5 \%$ sodium bicarbonate solution is considered to be close to the isotonic composition of blood. In terms of safety it does not adversely affect the animals after intravenous administration, as well as it does not cause damage to blood cells, osmotic and oncotic pressure and does not affect on the quality and veterinary and sanitary indicators of production in case of the need to slaughter animals.

Guided by the need to maintain the dynamic balance of the body of sick animals we sought to restore the body's physiological ability to self-regulation by restoring the homeostasis of the body to overcome the effects of pathogenic agents.

Based on the understanding that the administration of drugs to combat animal diseases can cause a number of specific and nonspecific biochemical and hematological changes, reflecting a certain degree of compensatory abilities of animal organism, we carried out some blood biochemical studies treated for the medicinal purposes with 5 \% sodium bicarbonate solution by intravenous infusion at the rate of $1 \mathrm{ml}$ per $1 \mathrm{~kg}$ of animal live weight. The blood sampling was made before the drug introduction and 2 hours, 4 hours, 8 hours, 24 hours, 48 and 72 hours after administration (Table 1).

These studies were planned with the aim to expand the existing ideas about the effects of this drug on the organism of treated animals, to determine the real opportunities for its general application in combating animal diseases accompanied by damage to the organs and systems of the body with intoxication symptoms.

However, it should be noted that an objective assessment of the effects of the studied drug on the body of treated animals can only be given on the basis of biochemical studies involving the study of transaminase activity and other tests that allow an assessment of organ pathology in animals and ensure physiologically normal functioning of many enzymes, hormones and the whole organism.

The results of biochemical studies of blood serum of cattle treated with $5 \%$ sodium bicarbonate solution are given in Table 1.

In order to early diagnose pathologies of myocardium and skeletal muscles, a biochemical blood test to measure the amout of CPK (creatine phosphokinase) was performed. Through the content of CPK, it was established that the enzyme activity in animals before the introduction of $5 \%$ aqueous solution of sodium bicarbonate has 82 $\%$ increase above the upper limit of normal values.

2 hours after drug administration, a significant decrease in CPK activity was observed. After that, a gradual increase over the entire period of experimental studies was observed: after 4 hours by $1.92 \%$, after 8 hours by $6.72 \%$, after 24 hours by $9.93 \%$, after 48 hours by $13.68 \%$ and after 72 hours by $16.52 \%$. 
TABLE 1: Biochemical parameters of blood serum of cattle with nodular dermatitis.

\begin{tabular}{|c|c|c|c|c|c|c|c|c|}
\hline Time Indicators & $\begin{array}{c}\text { Before } 5 \\
\% \\
\text { solution } \\
\text { administ- } \\
\text { ration }\end{array}$ & $\begin{array}{l}2 \text { hours } \\
\text { after } \\
\text { administ- } \\
\text { ration }\end{array}$ & $\begin{array}{l}4 \text { hours } \\
\text { after } \\
\text { administ- } \\
\text { ration }\end{array}$ & $\begin{array}{l}8 \text { hours } \\
\text { after } \\
\text { administ- } \\
\text { ration }\end{array}$ & $\begin{array}{l}24 \text { hours } \\
\text { after } \\
\text { administ- } \\
\text { ration }\end{array}$ & $\begin{array}{l}48 \text { hours } \\
\text { after } \\
\text { administ- } \\
\text { ration }\end{array}$ & $\begin{array}{l}72 \text { hours } \\
\text { after } \\
\text { administ- } \\
\text { ration }\end{array}$ & Standard \\
\hline Creatinine \% & 295.5 & 155.49 & 165.51 & 173.31 & 178.53 & 184.62 & 189.23 & 55.8--162.4 \\
\hline Carotene mg \% & 0.09 & 0.11 & 0.13 & 0.08 & 0.08 & 0.95 & 0.10 & $0.4--1.0$ \\
\hline $\begin{array}{l}\text { Total protein } \mathrm{g} \\
\%\end{array}$ & 7.8 & 8 & 7.97 & 7.99 & 7.92 & 7.90 & 7.85 & $7.2--8.6$ \\
\hline Calcium mmol & 2.6 & 1.8 & 2.32 & 2.30 & 2.90 & 2.80 & 2.70 & 2.5--3.1 \\
\hline $\begin{array}{l}\text { Phosphorus } \\
\mathrm{mmol} / \mathrm{l}\end{array}$ & 2.9 & 3.36 & 3.09 & 2.89 & 2.92 & 2.91 & 2.90 & $1.4--2.5$ \\
\hline AST units/I & 103.3 & 90.97 & 112.31 & 113.66 & 113.75 & 112.53 & 113.87 & 45.3--110.2 \\
\hline ALT units/I & 36.2 & 44.13 & 51.81 & 5161 & 50.17 & 49.65 & 47.54 & 6.9--35.3 \\
\hline Glucose sol/l & 1.9 & 2.02 & 1.97 & 2.47 & 2.49 & 2.85 & 3.42 & $2.3-4.1$ \\
\hline Vit. E mg\% & 0.5 & 0.55 & 0.52 & 0.53 & 0.54 & 0.56 & 0.58 & $0.4--1.5$ \\
\hline Urea sol/l & 5.0 & 5.69 & 5.09 & 5.99 & 5.85 & 5.90 & 5.72 & 2.8--8.8 \\
\hline $\begin{array}{l}\text { Reserve } \\
\text { alkalinity vol. \% } \\
\mathrm{CO}_{2}\end{array}$ & 37 & 41.46 & 45.44 & 48.91 & 48.91 & 4785 & 48.87 & $46--66$ \\
\hline
\end{tabular}

In our opinion, a significant increase in the indicator's activity before drug introduction was $82 \%$ higher than the upper limit of the norm due to the toxic effects on the body of sick animals associated with significant damage to the muscle tissue of other organs and body systems, which is a precursor to unfavorable forecasts.

The fluctuation range of the studied indicator in the period of experimental studies, starting from the first 2 hours after the administration of drug, varied within the limits of physiological norms, which indicates the removal of toxic effects.

The study of the activity of aspartate aminotransferase proved the fact that the activity of this enzyme before the introduction of $5 \%$ aqueous solution of sodium bicarbonate was within the boundaries of physiological norms and its slight increase was observed over the entire study period.

The established changes in the biochemical parameters of total protein, carotene, glucose, calcium and phosphorus, vitamin E and urea varied within the limits of physiological normal values; no significant changes were stated for the entire period of experimental studies.

The study of alanine aminotran-spherase activity showed that the activity of the enzyme before the administration of drug was within the limits of physiological norms; 
2 hours after the administration of $5 \%$ aqueous solution of sodium bicarbonate the enzyme activity increased up to $25 \%$ and after 4 hours it increased up to $46,77 \%$ with its gradual decrease down to $34.67 \% 72$ hours after the beginning of the study.

In our opinion, such indicators of enzyme activity in the organism of animals are due to the specific features of physiological state of the organism of animals in the process of carrying out the experimental studies.

In the process of conducting studies of alkaline reserve, a substantial decrease in the studied indicator was established, which indicates a sharp shift in the acid-base balance of the body towards acidosis.

It should be noted that a significant increase in the activity of the indicator under study (alkaline reserve vol. \% $\mathrm{CO}_{2}$ ) in treated animals was observed after 2 hours after drug administration with a further gradual increase up to 72 hours after the beginning of experiment. According to the results of analysis for the period of study, the increase in the activity of studied indicator was noted at $32.2 \%$, which reaches the level of average values within the physiological normal values.

Summing up the results of the studies, it can be said that the use of $5 \%$ aqueous solution of sodium bicarbonate with nodular dermatitis of cattle by the method of intravenous infusion at a dose of $1 \mathrm{ml}$ per $1 \mathrm{~kg}$ of animal live weight contributes to a significant decrease in toxic effects on the body.

In our opinion, a significant decrease in toxic effects on the body of treated cattle, is due to the fact that the activity of the infectious-parasitic system was carried out by normalizing cellular processes, by preventing changes in the salt composition of aquatic environment in the body, by preventing disorders of physiological equilibrium between acid and alkali levels in the body, which contributed to the preservation of constancy of biochemical composition of blood plasma and intercellular fluid, which further contributed to the provision of optimal conditions for functioning in normal physiological mode of all body cells, first of all, brain cells.

The indicators of established biochemical changes in the body of treated animals varied within physiological norms.

\section{Conclusion}

Summarizing the results of this study it can be concluded that if a disease is detected in a timely manner and in the first stage of nodular dermatitis, the treatment is initiated using the above-mentioned method of $5 \%$ sodium bicarbonate solution at a dose of 1 
$\mathrm{ml}$ per $1 \mathrm{~kg}$ of live weight of cattle. There is a significant decrease in toxic effects on the body by eliminating the negative acid load on the body of sick animals.

Thus, in case of nodular dermatitis, the intravenous infusion of a $5 \%$ aqueous solution of sodium bicarbonate helps restore homeostasis in the body and maintain its dynamic equilibrium. Besides, it ensures a significant increase in the resistance of the body of animals, the restoration of physiological ability of the body to self-regulate and overcome the effectsof pathogenic agents. Moreover, it helps reduce the economic damage to livestock.

In our opinion, the administration of this drug by veterinary specialists creates real prerequisites for a significant improvement of symptomatic and pathogenetic treatment by stimulating and accelerating the development of specific immunity against both viral and bacterial components as well as overcoming the effects of pathogenic agents by restoring the body's physiological ability to self-regulation.

Considering the detrimental effect of the disease on the productivity of dairy herds, reduced vitality and reproductive function, skin damage, development of permanent immunosuppression, etc., a significant increase in the economic efficiency of the veterinary measures and the possibility of obtaining animal-safe products of high sanitary quality plays an important role.

\section{References}

[1] Makarov., V.V., Makarov, V.V., Gruby, V.A., Gruzdev, K.N., Sukharev, O.I. (2012). OIE list and transboundary animal infections. Vladimir: Federal Center for Animal Health, pp. 76--79.

[2] Vatsaev, Sh.V. Chernykh, O.Yu., Lysenko, A.A. et al. (2018). Correction of cattle body homeostasis in case of nodular dermatitis Collection of Scientific Papers, iss. 27. Krasnodar, pp. 242--250.

[3] Mishchenko, A.V., Mishchenko, V.A. (2014). Epizootic situation on transboundary and economically significant infectious diseases of cattle in Russia in 2013. Proceedings of the International Conference Topical Veterinary Problems in Dairy and Beef Cattle. Kazan.

[4] Vatsaev, Sh.V., Chernykh, O.Yu.. Lysenko, A.A.. Konovalov, M.G. (2017). Evaluation of biochemical blood parameters in nodular dermatitis of cattle in the Chechen Republic. Scientific Journal Proceedings of Kuban State Agrarian University, no. 2(65), pp. 101--107.

[5] OIE Terrestrial Animal Health Code, vol. 1--2 (2014). 
[6] Vatsaev, Sh.V., Chernykh, O.Yu., Lysenko, A.A., Khakhov, L.A. (2016). Epizootological situation in case of cattle nodular dermatitis in the Chechen Republic. Scientific Journal Proceedings of Kuban State Agrarian University, no. 5(62), pp. 146--151.

[7] Buslovskaya, L.K. (2003). Energy metabolism and acid-base balance in farm animals when adapting to stress factors. Belgorod: Publishing house Bel. SU, p. 188.

[8] Vatsaev, Sh.V. (2008). Hypodermatosis of cattle (epizootology, species composition, population ecology) and the development of measures to combat it in the Chechen Republic. Stavropol.

[9] Vasiliev, E.A. (1985). Clinical biochemistry of farm animals. Moscow: Agropromizdat, p. 342. 